\title{
Research on the Deformation Law of Jointed Surrounding Rock during Tunnel Excavation Based on Hydromechanical Coupling
}

\author{
Yan Wang $\mathbb{D}$ and Mingfei Li $\mathbb{D}$ \\ School of Civil Engineering, Qingdao University of Technology, Qingdao, Shandong 266033, China \\ Correspondence should be addressed to Yan Wang; wangyantumu@qut.edu.cn
}

Received 5 February 2021; Revised 24 February 2021; Accepted 8 March 2021; Published 18 March 2021

Academic Editor: Zhengyang Song

Copyright ( 2021 Yan Wang and Mingfei Li. This is an open access article distributed under the Creative Commons Attribution License, which permits unrestricted use, distribution, and reproduction in any medium, provided the original work is properly cited.

\begin{abstract}
The coupling of the joint network and groundwater in rock under bias conditions has a significant impact on the deformation and failure of the surrounding rock due to tunnel excavation. This paper studies the deformation and failure of surrounding rock after tunnel excavation under different joint network and groundwater conditions. A finite element-based composite joint network modeling method is proposed in this paper, and the typical parameters of the surrounding rock, such as the plastic zone size, vertical displacement, and lateral displacement, are analyzed and compared through numerical calculations. According to the different stratum and hydraulic conditions considered, four numerical models under four different working conditions are established and studied. The deformation and failure laws of the surrounding rock during tunnel excavation are obtained. The results show that with a single joint network, when there is no influence of groundwater, the surrounding rock mainly undergoes shear failure at the arch crown after tunnel excavation. When the influence of groundwater is considered, there are differences in the mode of damage between the left and right sides of the tunnel. The stratum approximately $1 \mathrm{~m}$ from the invert breaks, and the right sidewall fails approximately $1 \mathrm{~m}$ from the measuring point. In rock with a composite joint network, when groundwater is not considered, two kinds of failures occur in the surrounding rock near the tunnel; however, the surrounding rock far from the tunnel is dominated by shear failure. The stratum approximately $3.5 \mathrm{~m}$ from the arch crown fractures and the surrounding rock within approximately $5.5 \mathrm{~m}$ from the measurement point on the right sidewall undergoes separation failure. Under the dual effects of joints and groundwater, soft rock deforms considerably. The total hydraulic gradient decreases from left to right before and after tunnel excavation. The total hydraulic gradient of the composite joint network strata is generally smaller than that of the single joint network. In the composite joint network strata, the total hydraulic gradient near the tunnel changes dramatically. This research can provide a reference for tunnel engineering under similar conditions.
\end{abstract}

\section{Introduction}

In recent years, China's transportation infrastructure has developed rapidly. In particular, in Southwest China, the construction scale of mountain tunnels and railway tunnels continues to grow [1]. Because of the many mountains and hills in Southwest China and the corresponding geological processes, many discontinuous structures, such as joints, cracks, and faults, are present in the strata in this area. Boundaries between soft and hard strata also constitute a typical weak structural plane. Therefore, it is inevitable that a tunnel built under these conditions crosses different types of weak structural surfaces. In addition, building tunnels in mountainous areas are often affected by bias load [2]. Under the combined action of the bias load and discontinuous structure, the deformation and failure laws of the rock surrounding a tunnel are very different from those of homogeneous layers. Another issue that cannot be ignored is the influence of groundwater. Weak structural surfaces such as joints, cracks, and faults act as conduits for water flow, and hydromechanical coupling has aggravated the destruction of tunnel-surrounding rock. The deformation law of jointed 
rock surrounding a tunnel, considering the coupling of the mechanical behavior and hydraulic processes, needs to be further studied.

Many scholars have studied the failure modes and stability effects of tunnel excavation on jointed rock layers. Through orthogonal experiments, Chen et al. [3] discussed the failure mode of shallowly buried and large-span subway tunnels and analyzed the influence of rock mass structure parameters on tunnel failure. The results indicate that the failure modes of all the tested models are shear or tension failure of the overburden strata along weak planes corresponding to randomly distributed joints, which eventually leads to the occurrence of staggered traction slip collapses and clear slip surfaces. Based on the concept of representative elementary volume (REV) and synthetic rock mass (SRM) modeling technology, Wang and Cai [4] proposed a discrete fracture network-discrete element method (DFN-DEM) multiscale modeling approach for determining the response of jointed rock masses to excavation. Roy et al. [5] used the Voronoi subdivision scheme in a framework based on discrete elements to simulate massive rock masses. The prediction model of the convergent strain of a tunnel is constructed by considering the uncertainty in the joint parameters and field stress ratio. Deng et al. [6] used the DEM method to numerically simulate the damage of an existing circular tunnel under the action of an explosion shock wave. The size of disturbance areas such as the destruction area, open area, and shear area around the circular tunnel and the peak particle velocity (PPV) on the tunnel surface are used to analyze tunnel destruction. The direction of the joints in the rock mass around a tunnel has a great influence on the tunnel damage, while the initial stress around a tunnel has relatively little influence on the tunnel failure. Wang et al. $[7,8]$ studied the excavation of shield tunnels with joints in an upper soft unit and a lower hard unit and proposed a Bayesian network-based dynamic risk assessment method for deep tunnel construction. The results of previous research suggest that under these conditions, the surface settlement caused by tunnel excavation is mainly affected by the elastic modulus and cohesion of the surrounding rock. The above studies mostly focus on the stability of tunnel excavation under the influence of a single joint. Numerical methods are mostly used to study the influence of different angles, spacings, thicknesses, and other joint characteristics on the stability of surrounding rocks and tunnels. However, research on the effect of the joint network and surrounding rock properties on tunnel excavation is not comprehensive enough.

Many studies have been performed on the mechanical properties of jointed rock masses. Bahrani and Kaiser [9] used a unique particle element modeling method to simulate jointed rock masses with various joint interlocking degrees and studied the influence of block shape, joint strength, and joint surface condition on the finite peak strength. The results from this investigation confirm that strength equations based on the geological strength index (GSI) underestimate the confined strength of highly interlocked and nonpersistently jointed rock masses. Zhao et al. [10] deduced a three-point modeling method that can consider arbitrarily arranged joints and applied it to discrete element simulation. The influence of joints on the mechanical behavior and failure modes of jointed rock specimens was studied. The results show that the joint angle (considering alpha, beta, and gamma) and resonant column apparatus (RCA) have a significant effect on the resulting sigma $(t)$ and failure mode, while $n$ has a significant effect on $E-t$. Changjiang et al. [11] established a jointed rock mass model of a tunnel in bedded strata. Using the finite element strength reduction method, the influences of the joint dip and joint spacing on the tunnel failure mode and stability were studied by assuming that the surrounding rock of the tunnel is a hard rock layer or interbedded hard rock and soft rock. After the tunnel in bedded strata is excavated, the surrounding rock will slide along a joint plane in the bedding direction and the surrounding rock with vertical bedding will bend and break. When the joint inclination angle changes, the damage degree and damage and range in these two directions will change accordingly, which affects the safety factor of the tunnel. The safety factor reaches its peak value when the inclination angle is $40^{\circ}$. The barrier function method based on the fmincon optimization function in MATLAB was used to determine the function of mapping the tunnel boundary to the unit circle in the complex plane, and the structural failure criterion for mapping convergence was established according to the underground reliability theory. Wu et al. [12] approximated a joint as a crack around the tunnel, studied the anisotropy of the stress intensity factor caused by the inclination and position of the crack, and proposed a modified layered tunnel for the classification of rock geomechanics (RMR) joint scoring parameters. The crack with an inclination angle of $45^{\circ}$ is the main structural surface of the jointed rock mass around the tunnel, and the corresponding cracks at various points around the tunnel have inconsistent effects on the tunnel. To study the mechanical properties of jointed rock masses, the physical and mechanical properties of prefabricated jointed specimens were measured mainly through indoor tests or numerical simulations. The previous research focuses on the mechanical properties of the rock itself and has little connection with engineering applications, such as tunnel excavation.

Some scholars have also conducted research on jointed rock tunnels by coupling the hydraulic processes and mechanical behavior. Maleki [13] introduced a new method for estimating the inflow of groundwater in a tunnel excavated in a rocky environment. The main advantage of this model is that it takes into account the joint conditions in the tunnel and the direct influence of the tunnel radius, to separate the study of the joint set and the role of the crack system in the diversion of groundwater to the excavation hole. The analysis and empirical methods used to estimate the flow into the tunnel in current engineering practice cannot fully consider the impact of groundwater level drop. Moon and Fernandez [14] proposed an analysis method for estimating the inflow of groundwater considering the drop in groundwater level in a jointed rock mass. The solution of the proposed analysis is similar to the results of field observations and numerical analysis using the unique element method. This method can fully simulate the coupling of the 
hydraulic processes and joint behavior in the rock mass. Aiming at the problems that the inflow of water in fractured rock is greatly affected by the anisotropy of the rock and soil structure and that the assumed isotropic hydraulic coefficient is not efficient in calculating the amount of water that infiltrates into a tunnel in a jointed rock mass, Farhadian et al. [15] proposed a fractured rock empirical formula for describing the hydraulic conductivity in fractured rock masses. The empirical equation can be used to accurately predict the inflow of groundwater into a tunnel and thus the amount of water entering the tunnel.

Discrete element numerical simulations [16-20], mechanical tests [21-24], and model tests [25-28] have been used to study the surrounding rock deformation laws of jointed rock in underground engineering. As an emerging technology, 3D printing is also used in the research of jointed rock masses. Xia et al. [29] proposed and verified a new method to accurately reconstruct an irregular CJRM structure using 3D printing. This method can be used in the design of irregular CJRM in rock engineering. To overcome the deficiency of natural joint specimens with the same surface morphology for experimental studies, Jiang et al. [30] present a technical method for replicating natural joint specimens that incorporates two advanced techniques-threedimensional (3D) scanning and 3D printing-using a computer-aided design (CAD) as the bridge. This method reduces the experimental error derived from the differences between replicate specimens containing natural joint morphology. Peridynamics, as a novel numerical method, is increasingly used in the study of rock fractures and joint crack propagation. Wang et al. and Zhou et al. [31-33] investigated crack propagation and coalescence behaviors in rock specimens containing preexisting open flaws under uniaxial compression using peridynamics. Most studies are limited to a single factor, such as the characteristic parameters of the joints, the size of the tunnel, or the volume of the water flow. The influence of multiple factors is commonly encountered in actual engineering. Therefore, it is necessary to study the deformation and failure laws of tunnel excavation in different rocks under the influence of both the joint network and hydromechanical processes. Compared with DEM, FLAC, PFC, and other numerical calculation methods, the FEM method has higher efficiency in linear solving. The DEM method is mostly used in the calculation of rock fractures. FLAC is widely used in the calculation of large deformation of soft rock. PFC is widely used in fluid calculations. The RS2 finite element software selected in this paper has a rich built-in joint network model and can perform hydraulic coupling calculations. Based on an engineering example of a railway tunnel in Southwestern China, the finite element method is used to establish a numerical model to study the deformation and failure laws of surrounding rock with different joint networks during tunnel excavation under a bias load. By comparing and analyzing the tunnel surrounding rock deformation parameters of tunnels located in rock with a single joint network and rock with a composite joint network, with and without hydraulic coupling, typical parameters such as the horizontal and vertical displacements and plastic zone size of the surrounding rock are analyzed under different conditions. The stability of the surrounding rock of a tunnel under the combined action of groundwater flow and joint networks is discussed in this paper, which can provide a reference for similar tunnel projects.

\section{The Joint Network Equivalent Model}

According to the equivalent model of a joint network in strata summarized by Yabin [34] and Weihuan [35], the one-group joint model, two-group joint model and $N$-group joint model are analyzed.

2.1. The One-Group Joint Model. Suppose there is a group of joints in a two-dimensional coordinate system; the average distance between two joint surfaces is $d$, and the angle between the normal direction of the joint surface and the horizontal direction is $\varphi$, as shown in Figure 1.

The stress-strain relationship of the joint in the local coordinate system is as follows:

$$
\left\{\begin{array}{c}
\sigma_{x}{ }^{\prime} \\
\sigma_{y}^{\prime} \\
\sigma_{z}^{\prime}
\end{array}\right\}=M\left[\begin{array}{ccc}
1-n \mu_{2}^{2} & \mu_{2}\left(1+\mu_{1}\right) & 0 \\
\mu_{2}\left(1+\mu_{1}\right) & \frac{1-\mu_{2}^{2}}{n} & 0 \\
0 & 0 & \frac{G_{2}}{M}
\end{array}\right]\left\{\begin{array}{c}
\varepsilon_{x}{ }^{\prime} \\
\varepsilon_{y}^{\prime} \\
\varepsilon_{z}^{\prime}
\end{array}\right\}
$$

or

$$
\sigma^{\prime}=\left[D^{\prime}\right]\left\{\varepsilon^{\prime}\right\}
$$

where

$$
\begin{gathered}
M=\frac{E_{1}}{\left(1+\mu_{1}\right)\left(1-\mu_{1}-2 n \mu_{2}^{2}\right)}, \\
n=\frac{E_{2}}{E_{1}}, \\
G_{2}=\frac{1}{\left[((2(1+\mu)) / E)+\left(1 / K_{s} S\right)\right]}, \\
E_{2}=\frac{1}{\left[\left(1 / E_{1}\right)+\left(1 / K_{n} S\right)\right]}, \\
E_{1}=E, \\
\mu_{1}=\mu, \\
\mu 2=\left(\frac{E_{2}}{E_{1}}\right) \mu_{1}=n \mu_{1} .
\end{gathered}
$$

$E$ is the elastic modulus of the intact rock mass, and $\mu$ is the Poisson's ratio of the intact rock. $K_{n}$ and $K_{s}$ are the stiffness coefficients corresponding to the normal and tangential directions on the joint plane in the rock, respectively.

To convert the matrix $\left[\mathrm{D}^{\prime}\right]$ from the local coordinate system $x-y$ to the global coordinate system $X-Y$, the global 


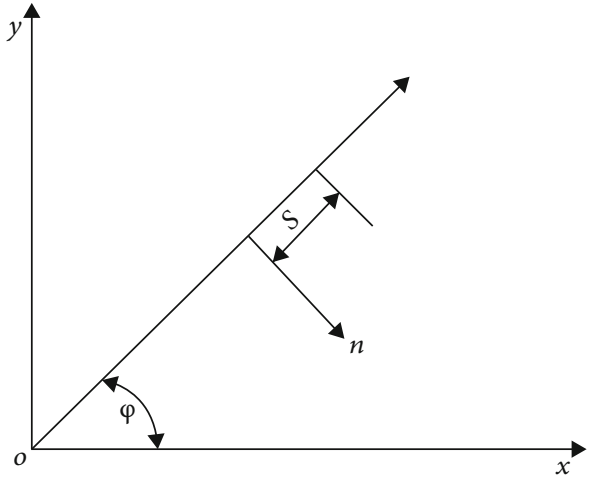

FIGURE 1: The one-group joint model in local and global coordinate systems.

coordinate system $[\mathrm{D}]$ can be obtained as follows:

$$
[D]=[L]\left[D^{\prime}\right][L]^{T},
$$

where

$$
[L]=\left[\begin{array}{ccc}
\cos ^{2} \theta & \sin ^{2} \theta & -2 \sin \theta \cos \theta \\
\sin ^{2} \theta & \cos ^{2} \theta & 2 \sin \theta \cos \theta \\
\sin \theta \cos \theta & -\sin \theta \cos \theta & \cos ^{2} \theta-\sin ^{2} \theta
\end{array}\right] .
$$

2.2. The Two-Group Joint Model. The two-group joint model is shown in Figure 2.

When there are two sets of joint planes in the surrounding rock, to simplify the calculation process, the interaction among joints is not considered. Instead, the contribution of each group of joints to the rock mass is calculated and algebraically superposed. In this case, the elastic matrix of the rock mass with joints can be written as follows:

$$
\begin{aligned}
{[D] } & =\left[D_{0}\right]+\left(\left[D_{1}\right]-\left[D_{0}\right]\right)+\left(\left[D_{2}\right]-\left[D_{0}\right]\right) \\
& =\left[D_{1}\right]+\left[D_{2}\right]-\left[D_{0}\right]=\sum_{i=1}^{2}\left[D_{i}\right]-\left[D_{0}\right]
\end{aligned}
$$

where $[D]$ is the elastic matrix when the rock is intact, $\left[D_{1}\right]$ is the elastic matrix when only the first group of rock joints is present, $\left[D_{2}\right]$ is the elastic matrix when only the second group of rock joints is present, $\left[D_{1}\right]-\left[D_{0}\right]$ is the influence of the first group of joints on the rock mass, and $\left[D_{2}\right]-\left[D_{0}\right]$ is the influence of the second group of joints on the rock mass.

2.3. The N-Group Joint Model. According to the calculation process when one and two groups of joints exist, the elastic matrix for the $\mathrm{N}$-group joint model in the $X-Y$ coordinate

\begin{tabular}{|c|c|c|}
\hline $\begin{array}{l}\text { Working } \\
\text { condition }\end{array}$ & Stratum condition & Hydraulic condition \\
\hline I & Single joint network & $\begin{array}{c}\text { Without } \\
\text { groundwater }\end{array}$ \\
\hline II & Single joint network & With groundwater \\
\hline III & $\begin{array}{l}\text { Composite joint } \\
\text { network }\end{array}$ & $\begin{array}{l}\text { Without } \\
\text { groundwater }\end{array}$ \\
\hline IV & $\begin{array}{l}\text { Composite joint } \\
\text { network }\end{array}$ & With groundwater \\
\hline
\end{tabular}

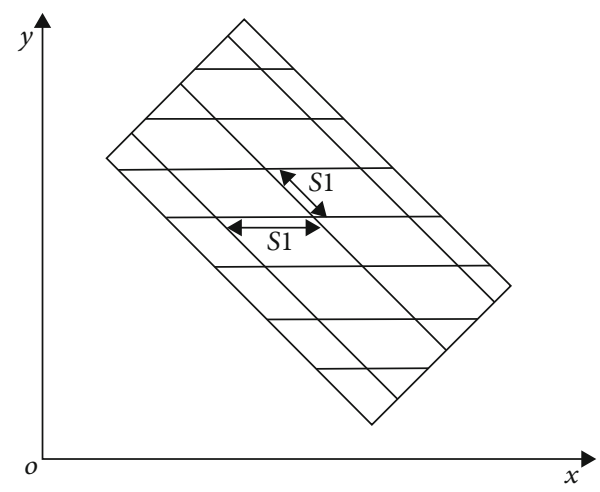

FIgURE 2: The two-group joint at global coordinate system.

TABLE 1: Numerical model conditions.

system can be calculated as follows:

$$
\begin{aligned}
{[D]=} & {\left[D_{0}\right]+\left(\left[D_{1}\right]-\left[D_{0}\right]\right)+\left(\left[D_{2}\right]-\left[D_{0}\right]\right)=\left[D_{1}\right] } \\
& +\left[D_{2}\right]-\left[D_{0}\right]+\cdots+\left[D_{n}\right]-\left[D_{0}\right]=\sum_{i=1}^{N}\left[D_{i}\right]-(n-1)\left[D_{0}\right],
\end{aligned}
$$

where $\left[D_{i}\right]=\left[L_{i}\right]\left[D_{i}^{\prime}\right]\left[L_{i}\right]^{T}$.

\section{Numerical Simulation Methodology}

3.1. Numerical Model Conditions. To study the deformation and failure laws of the surrounding rock with a single joint network and a composite joint network after tunnel excavation under the influence of the hydromechanical process, a comparative analysis numerical model was established with the finite element method. According to the two conditions of a single joint network and a composite joint network, the model is divided into two types. Among them, a single joint network corresponds to a hard rock stratum and a composite joint network corresponds to a hard rock stratum and a soft rock stratum. According to the two hydraulic conditions, including and excluding groundwater, the model is further divided into two types.

Therefore, according to the stratum conditions and hydraulic conditions, four working conditions, namely, working condition I, working condition II, working condition III, and working condition IV, are considered, as shown in Table 1. The groundwater is realized by setting different 


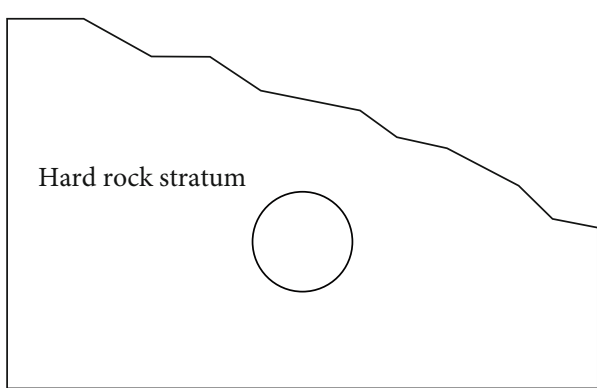

(a) Model with a single joint network

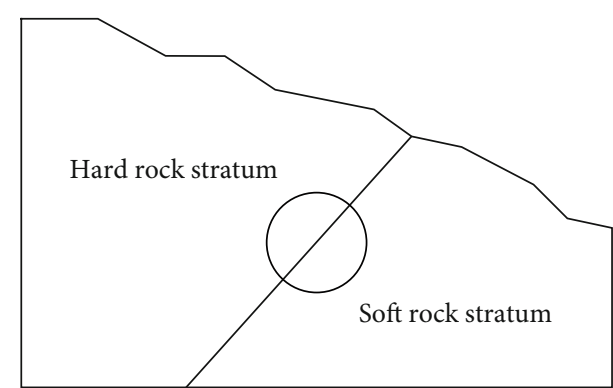

(b) Model with a composite joint network

FIgURe 3: Schematic models.

TABLE 2: Stratum parameters.

\begin{tabular}{|c|c|c|c|c|c|c|}
\hline Stratum & $\begin{array}{c}\text { Density } \\
\gamma\left(\mathrm{kN} / \mathrm{m}^{3}\right)\end{array}$ & $\begin{array}{c}\text { Elastic } \\
\text { modulus } E(\mathrm{GPa})\end{array}$ & $\begin{array}{l}\text { Poisson's } \\
\text { ratio } v\end{array}$ & $\begin{array}{l}\text { Cohesion } \\
c(\mathrm{MPa})\end{array}$ & $\begin{array}{c}\text { Internal } \\
\text { friction angle } \varphi\left(^{\circ}\right)\end{array}$ & $\begin{array}{c}\text { Tensile } \\
\text { strength } t(\mathrm{MPa})\end{array}$ \\
\hline $\begin{array}{l}\text { Hard } \\
\text { stratum }\end{array}$ & 26 & 20 & 0.3 & 1.6 & 55 & 0.8 \\
\hline $\begin{array}{l}\text { Soft } \\
\text { stratum }\end{array}$ & 22 & 6 & 0.35 & 0.6 & 45 & 0.35 \\
\hline
\end{tabular}

TABLE 3: Joint parameters.

\begin{tabular}{lcccc}
\hline Joint & Cohesion $c(\mathrm{MPa})$ & Internal friction angle $\varphi\left(^{\circ}\right)$ & Normal stiffness $N(\mathrm{MPa} / \mathrm{m})$ & Shear stiffness $S(\mathrm{MPa} / \mathrm{m})$ \\
\hline Joint 1 & 0.08 & 20 & 30000 & 3000 \\
Joint 2 & 0.03 & 15 & 10000 & 1000 \\
\hline
\end{tabular}

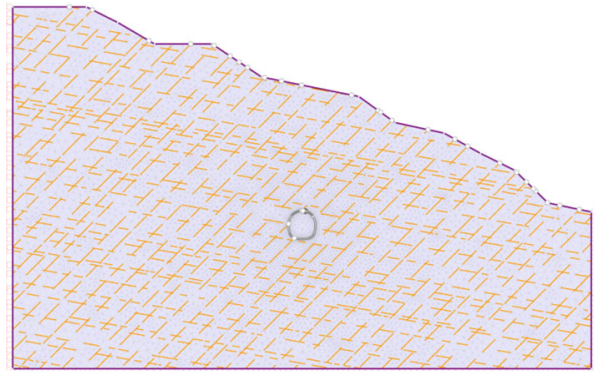

(a) Numerical model with a single joint network

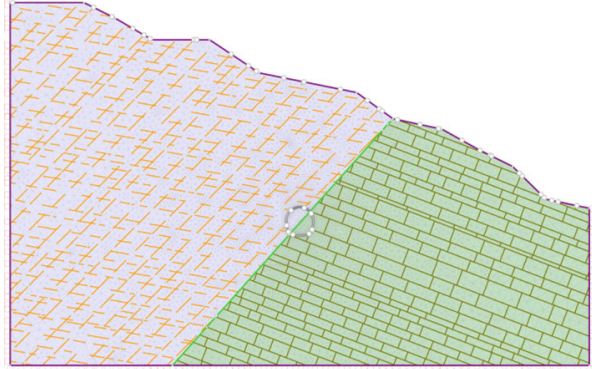

(b) Numerical model with a composite joint network

Figure 4: Numerical models.

total water heads at the left and right boundaries. According to the model boundaries, the water head on the left is $75 \mathrm{~m}$ and the water head on the right is $32.5 \mathrm{~m}$. The groundwater is set after the initial balance.

3.2. The Numerical Simulation Model. For the example of a railway tunnel project, numerical models are established by considering the abovementioned working conditions. When simulating working condition I and working condition II, the tunnel is placed in strata with a single joint network (simplified as hard rock). When simulating condition III and condition IV, the tunnel is placed in strata with a composite joint network (simplified as hard rock and soft rock). By default, the intersection of the hard and soft rocks runs diagonally through the center of the tunnel. Different model heights and initial stresses are used to achieve different bias loads. The models of a single joint network and a composite joint network are shown in Figure 3. For clarity, the tunnel is enlarged to a certain extent. The influence of the joint network on the direction of tunnel excavation has not been considered. The lining effect and excavation steps are not considered in the paper. Therefore, the $2 \mathrm{D}$ method was selected by the paper for calculation.

In the studied project, the width of the actual tunnel is $5.6 \mathrm{~m}$ and the height is $6.8 \mathrm{~m}$. The tunnel in the model has a width of $120 \mathrm{~m}$ and a height of $75 \mathrm{~m}$. The $x$ direction is the horizontal direction, and the $y$ direction is the vertical direction. The origin of the coordinates is at the center of the tunnel. The $x$ direction displacement is fixed at the left and right boundaries, the $y$ direction displacement is fixed at the lower 


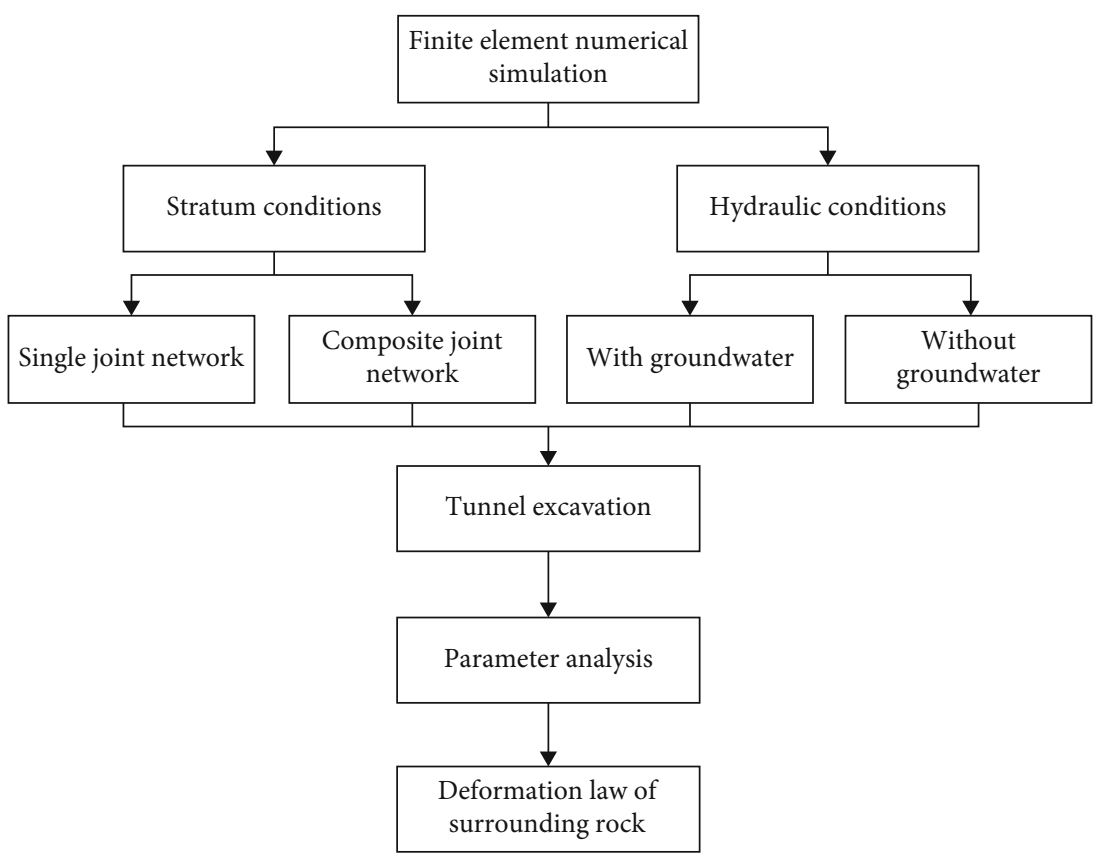

Figure 5: Numerical calculation steps.

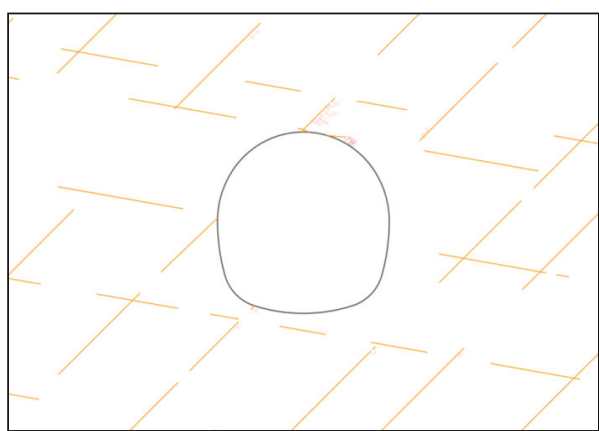

(a) Working condition I

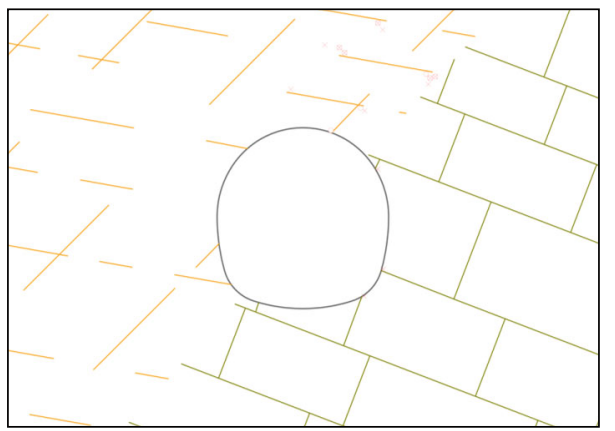

(c) Working condition III

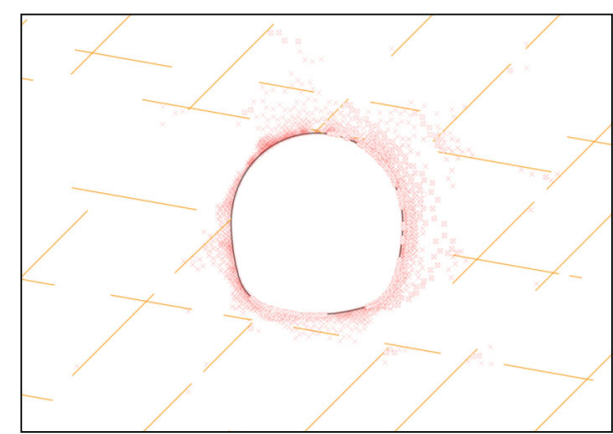

(b) Working condition II

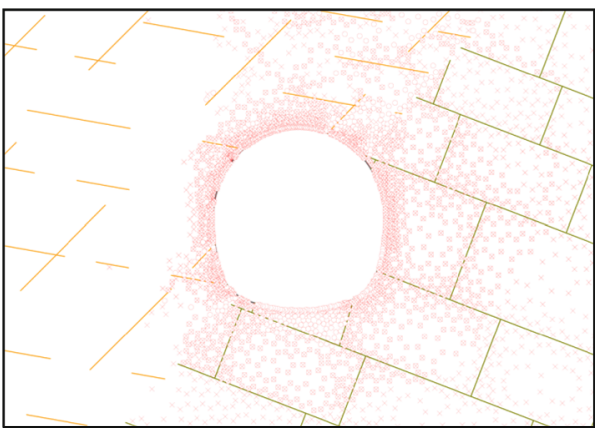

(d) Working condition IV

FIGURE 6: Surrounding rock plastic zone.

boundary, and the upper boundary is free. Each joint network is realized by setting different joint spacings and lengths and a joint inclination. Two hard rock joint networks are combined by combining two different parallel statistical models. Among them, one is generated according to a normal distribution with an average joint spacing of $3 \mathrm{~m}$ and a standard deviation of $0.8 \mathrm{~m}$. The other is generated according to a normal distribution with a mean distance between joints of $2 \mathrm{~m}$ and a standard deviation of $0.5 \mathrm{~m}$. The network formed by the interweaving of the two parallel statistical models is the joint network. The soft rock joint networks are generated by creating a cross-jointed model with a normal distribution with a mean value of $2 \mathrm{~m}$ and a standard deviation of $0.8 \mathrm{~m}$. The cross-joint spacing is generated according to a normal distribution with a mean value of $5 \mathrm{~m}$ and a standard deviation of $1 \mathrm{~m}$. The method of setting 

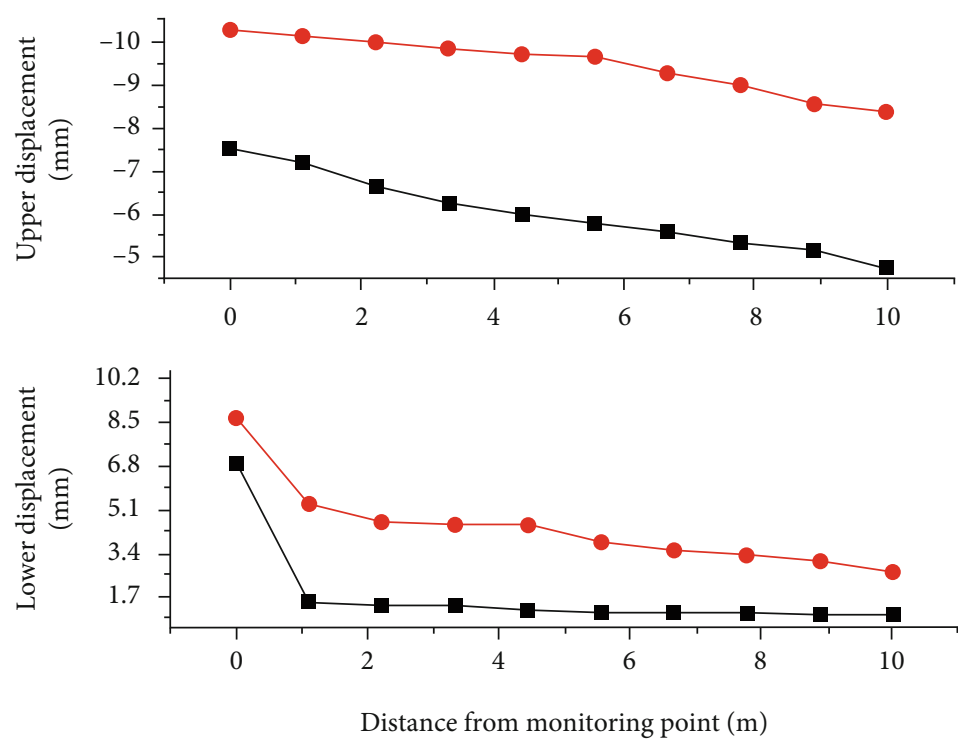

- Working condition I

- Working condition II

Figure 7: Vertical displacements of working conditions I and II.
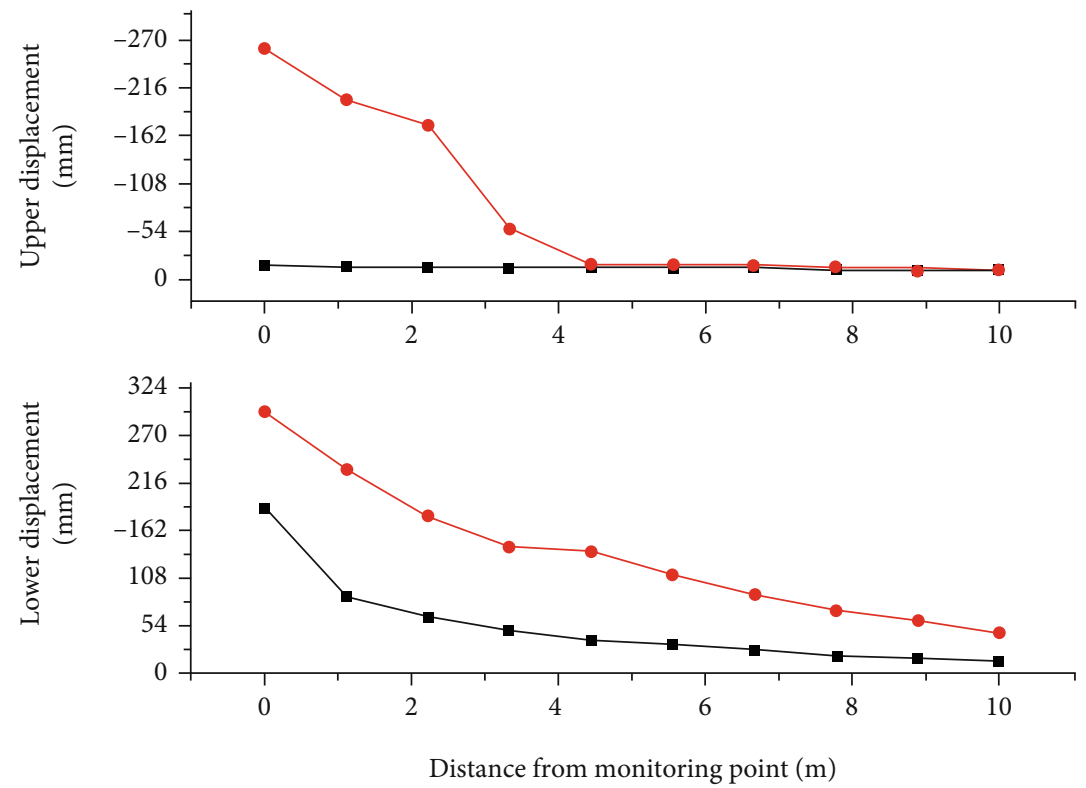

- Workintg conditon III

- Workintg conditon IV

FIgURE 8: Vertical displacements of working conditions III and IV.

the water head is used to simulate groundwater. The model has 22,832 triangular elements and 13,232 nodes. The formation parameters and joint parameters are shown in Tables 2 and 3 . Joint 1 represents the joints in the joint network in the hard strata, and joint 2 represents the joints in the joint network in the soft strata. The numerical models of the single joint network and composite joint network are shown in Figure 4.
When performing numerical calculations, according to the four different working conditions, the initial strata balance is performed and the initial displacement is reset. After tunnel excavation, the changes in the surrounding rock deformation parameters are analyzed and the surrounding rock deformation laws under the four working conditions are obtained. The full-face excavation method is adopted. The numerical calculation steps are shown in Figure 5. 

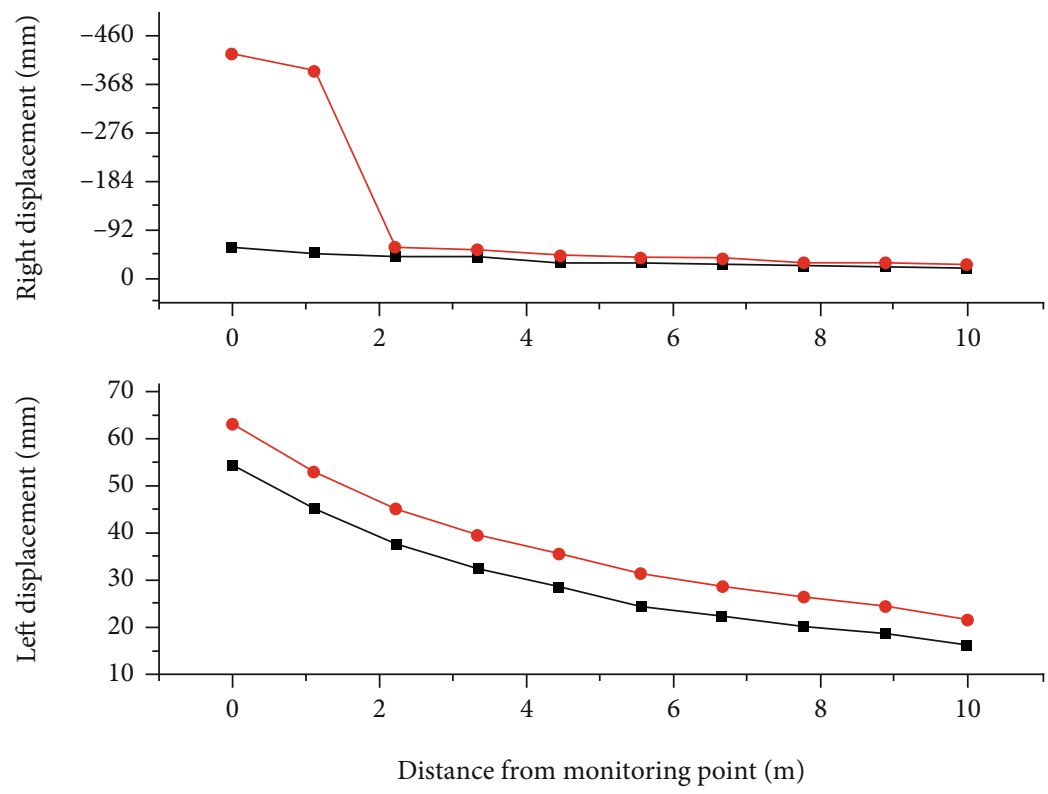

$\rightarrow$ Working condition I

$\multimap$ Working condition II

FIGURE 9: Horizontal displacements of working conditions I and II.
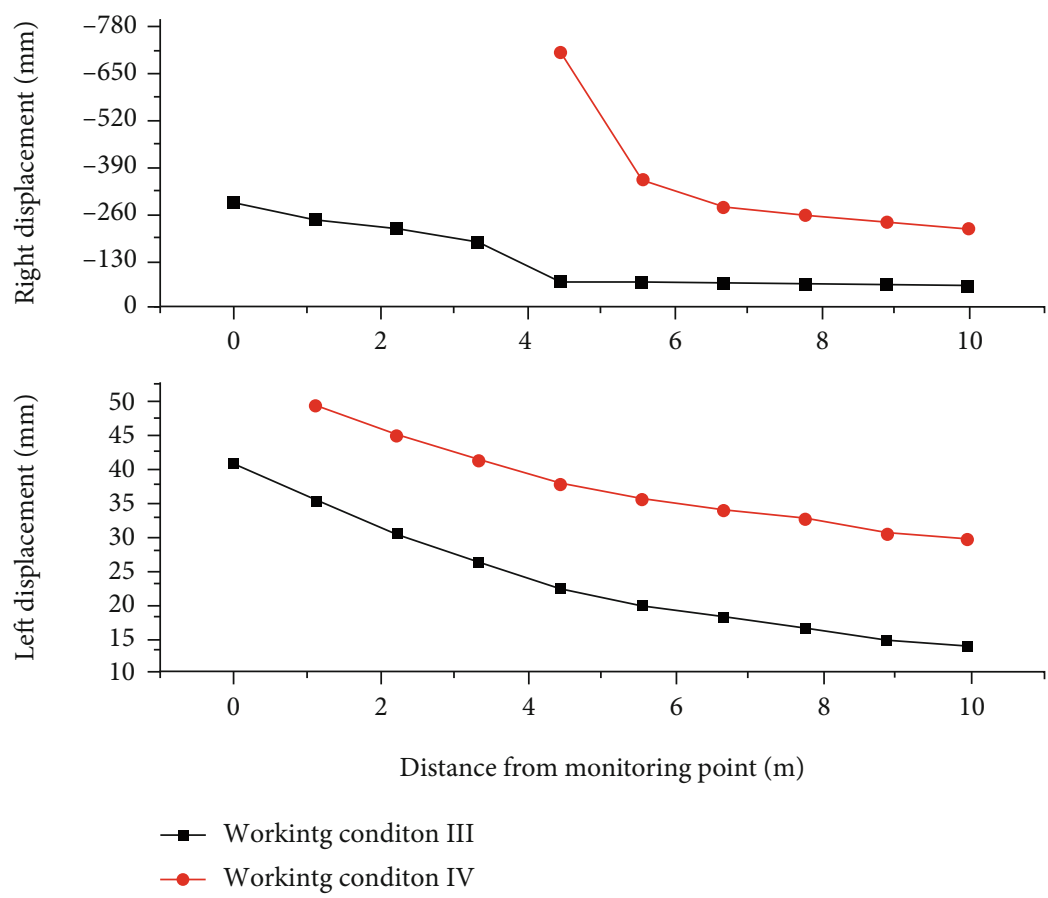

FIGURE 10: Horizontal displacements of working conditions III and IV.

\section{Analysis of Numerical Simulation Results}

According to the four numerical models corresponding to the different working conditions, numerical calculations are carried out during the tunnel excavation in strata with joints and the surrounding rock deformation parameters are analyzed and compared.
4.1. The Surrounding Rock Plastic Zone. According to the calculation results, the shape of the plastic zone in the surrounding rock caused by tunnel excavation is obtained under the four working conditions, as shown in Figure 6.

The shape of the plastic zone in the surrounding rock shows that with a single joint network in hard rock and without the influence of groundwater, the surrounding 


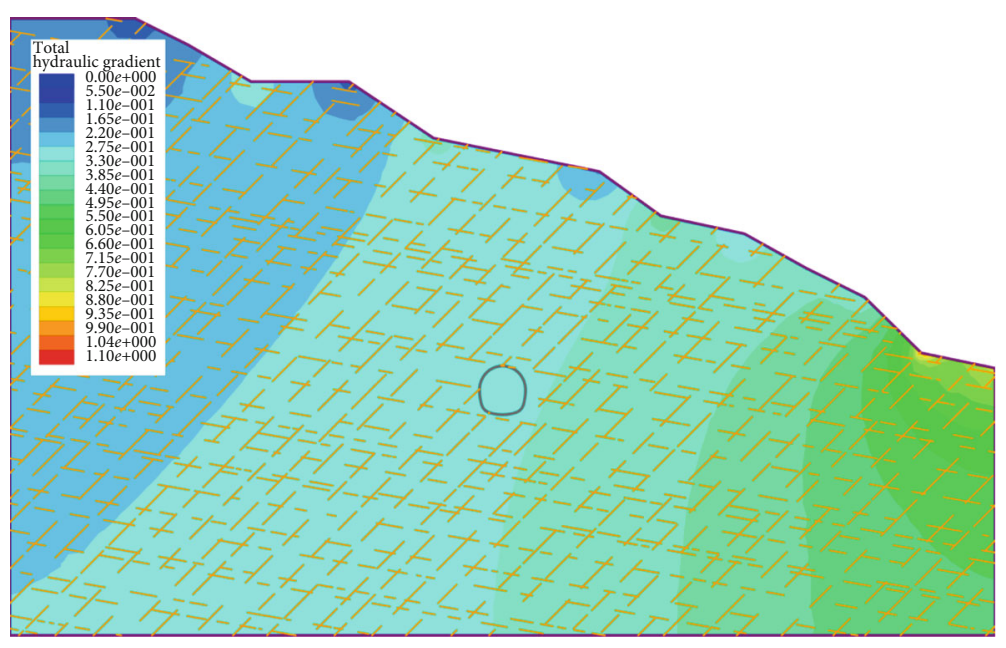

(a) Before tunnel excavation

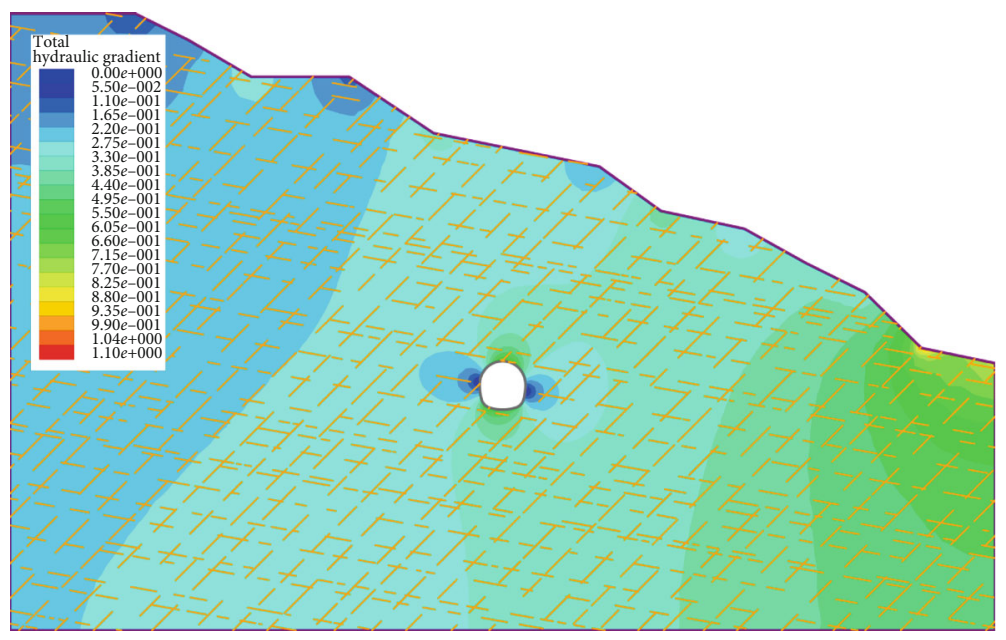

(b) After tunnel excavation

FIgURe 11: Total hydraulic gradient with a single joint network.

rock mainly undergoes shear failure at the vault after tunnel excavation. Because of the existence of a set of crossjoints at the arch crown, the strength of the surrounding rock at the arch crown is weak, so shear failure occurs there. For the single joint network in hard rock under the influence of groundwater, the surrounding rock near the tunnel yielded but the yield range was not large. The surrounding rock on the left of the tunnel is dominated by shear failure, while the surrounding rock on the right undergoes both shear and tensile failure. For the composite joint network, without the influence of groundwater, tunnel excavation mainly produces a small amount of damage in the surrounding rock at the junction of the soft and hard strata. Under the influence of the composite joint network and groundwater, the surrounding rock near the tunnel suffers large-scale damage, mainly concentrated in the soft rock. The surrounding rock above the arch crown and below the invert yields in a large area. Two kinds of failures occur near the tunnel at the same time, whereas shear failure is the main failure at the rock far from the tunnel.
4.2. Vertical Displacement. To study the law of the vertical deformation of the surrounding rock caused by tunnel excavation under the four working conditions, two monitoring points are set at the midpoints of the tunnel arch crown and invert and the vertical displacements at $10 \mathrm{~m}$ above and below the two monitoring points are selected for analysis. The vertical displacements of working condition I and working condition II are shown in Figure 7 . When only a single joint network is present, the vertical displacement affected by groundwater is greater than that without the influence of groundwater. The stratum displacement approximately $1 \mathrm{~m}$ from the invert decreases rapidly, indicating that the stratum fractures are there. The vertical displacement tends to be stable after the rock breaks.

The vertical displacements of working condition III and working condition IV are shown in Figure 8. In the rock with a composite joint network, the vertical displacement affected by groundwater is also greater than that without the influence of groundwater. The displacement of the surrounding rock at approximately $3.5 \mathrm{~m}$ from the arch crown decreases rapidly, indicating that the formation breaks. 


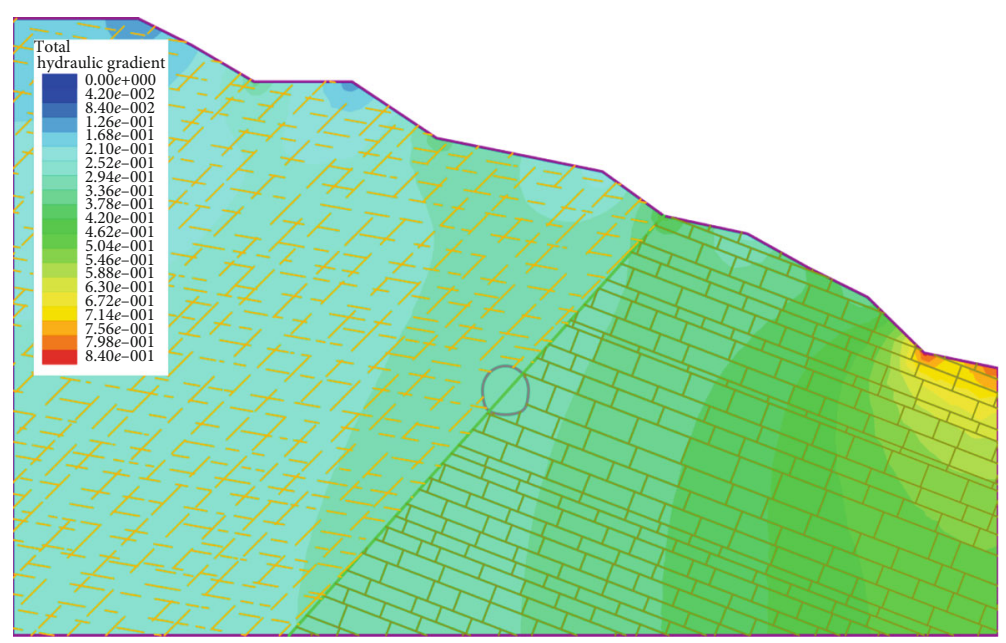

(a) Before tunnel excavation

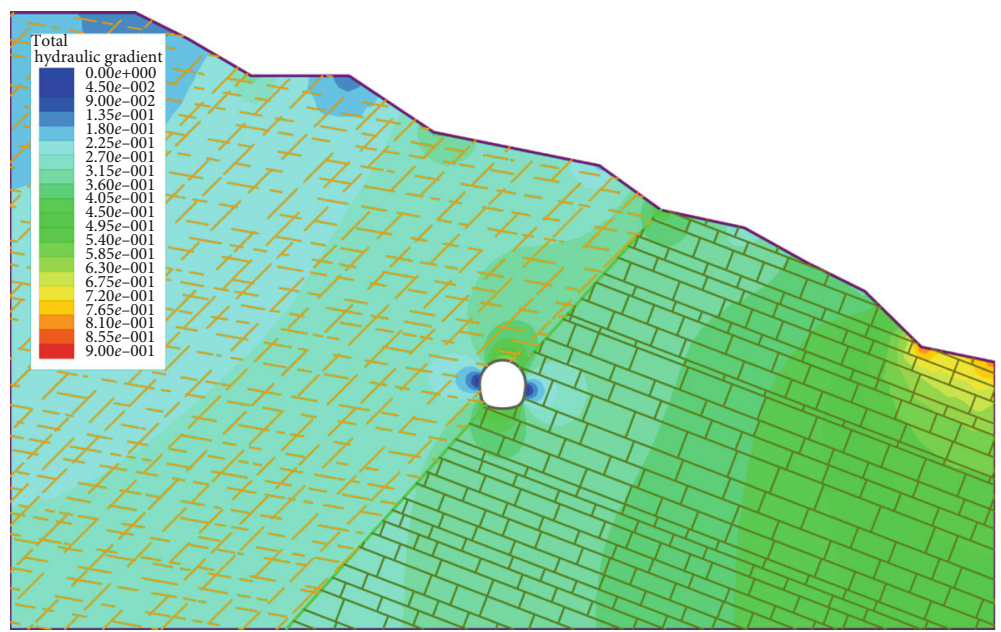

(b) After tunnel excavation

FIgURE 12: Total hydraulic gradient with a composite joint network.

Comprehensive analysis suggests that the yield fractures of the strata may be affected by the joints, which are weak structural planes, resulting in a decrease in the strength of the strata. After the tunnel is excavated, under the influence of a coupled hydromechanical process, separation failure occurs.

4.3. Horizontal Displacement. To study the law of horizontal deformation of the surrounding rock caused by tunnel excavation under the four working conditions, two measuring points were set at the midpoints of the left and right sidewalls of the tunnel and the horizontal displacements within $10 \mathrm{~m}$ from the two measuring points were selected for analysis.

The horizontal displacements of working condition I and working condition II are shown in Figure 9. In the rock with a single joint network, the displacement at the right side of the tunnel sidewall approximately $2 \mathrm{~m}$ from the measuring point is relatively close. When there is groundwater, the right lateral displacement of working condition II suddenly decreases at approximately $1 \mathrm{~m}$, indicating that the right sidewall is damaged at this time. Except for the large displacement of the surrounding rock within $2 \mathrm{~m}$ from the measuring point, there is little difference in the horizontal displacement on the right with and without considering groundwater. The displacement of the sidewall on the left side of the tunnel changes more consistently under the influence of groundwater, and the displacement of the surrounding rock is larger under this condition. The difference in the displacement of the surrounding rock on both sides of the tunnel is clearly affected by not only the influence of groundwater but also the bias load.

The horizontal displacements of working condition III and working condition IV are shown in Figure 10. When the tunnel is located in rock with a composite joint network, due to the action of groundwater, the horizontal displacement of the surrounding rock on the right side of the sidewall has exceeded the limit, that is, the displacement is larger than the width of the tunnel. Therefore, after removing the limit value, the horizontal displacement curve of the surrounding rock on the right side of the sidewall is obtained with and without considering groundwater. The surrounding rock within approximately $5.5 \mathrm{~m}$ from the measuring point undergoes separation failure, indicating that the deformation of the jointed soft rock is significantly affected by the groundwater. When there is no groundwater effect, the horizontal 


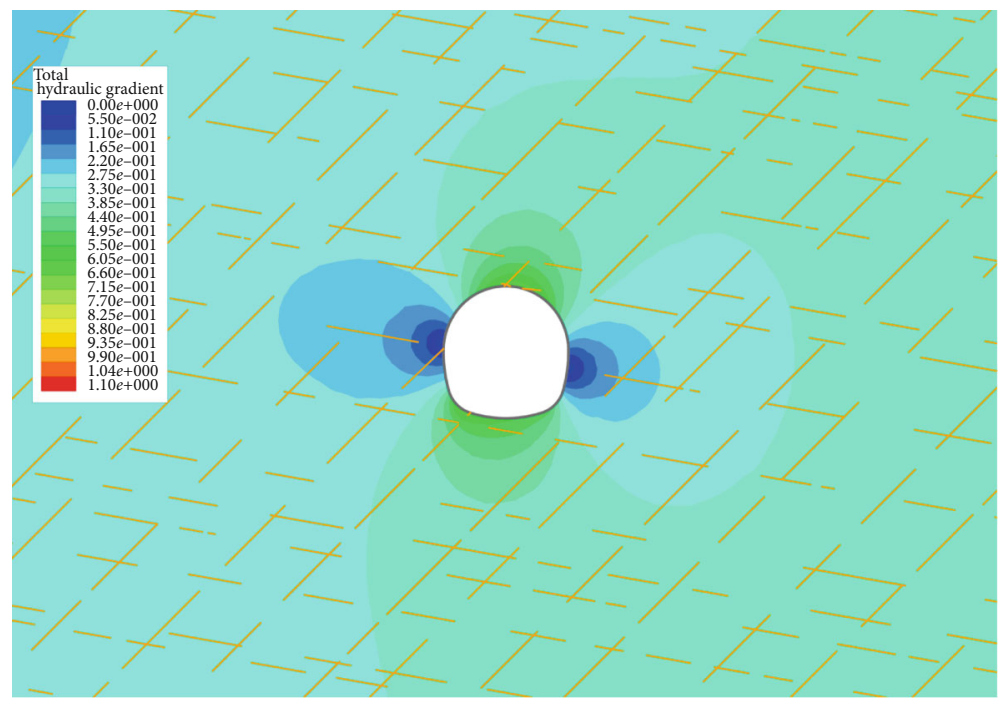

(a) Single joint network

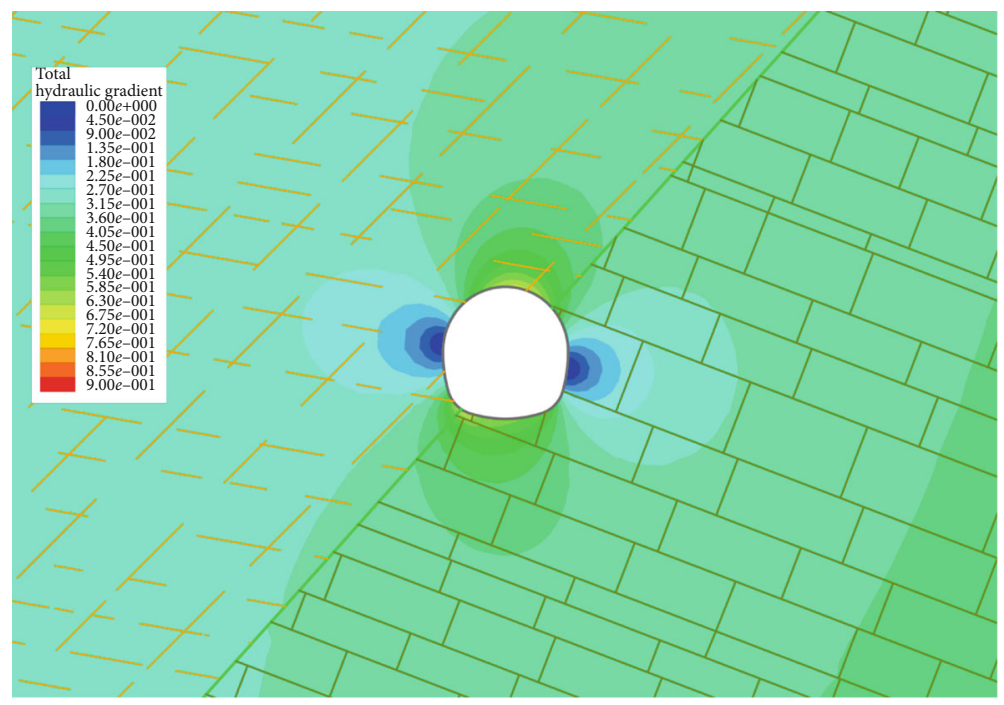

(b) Composite joint network

Figure 13: Total hydraulic gradient after tunnel excavation.

deformation of the surrounding rock on the left sidewall is relatively consistent but there is also an overlimit value at the monitoring point on the left sidewall, indicating that the left sidewall is also damaged. The displacement of the jointed soft rock under the influence of groundwater increases significantly toward the monitoring point and is approximately 10 times that of the jointed hard rock. Under the dual effects of joints and groundwater, soft rock deforms considerably.

4.4. Total Hydraulic Gradient. Under the two conditions involving joint networks in strata, the hydraulic gradient cloud maps with groundwater after excavation are shown in Figures 11 and 12.

It can be seen from the figures that in the two joint network situations, due to the difference in water height on both sides of the model, the total hydraulic gradient decreases from left to right before the tunnel is excavated. After the tunnel is excavated, the total hydraulic gradient of the two joint network situations still shows a decreasing distribution from left to right. Comparison of the total hydraulic gradient of the two joint network situations after tunnel excavation reveals that the total hydraulic gradient of the composite joint network is generally smaller than that of the single joint network. In the composite joint network, the total hydraulic gradient near the tunnel changes dramatically. Due to the two different joint networks, the hydromechanical effect is clearly observed in Figure 13.

\section{Conclusions}

Based on the modeling of rock with a single joint network and rock with a composite joint network, the deformation and failure laws of the surrounding rock after tunnel 
excavation are studied under the influence of bias load and groundwater. Taking a railway tunnel as the engineering background, the finite element numerical simulation method is used. For the tunnels located in two different stratum conditions of a single joint network in hard rock and a composite joint network in soft and hard rock, comprehensively considering the groundwater and bias conditions, four numerical models were established, corresponding to working condition I, working condition II, working condition III, and working condition IV. Through numerical calculation, the typical surrounding rock deformation parameters, such as the plastic zone shape, vertical displacement, and horizontal displacement, under these four working conditions are analyzed and compared, and the deformation and failure laws of the surrounding rock after tunnel excavation are obtained under the different working conditions. The main conclusions are as follows:

(1) In the hard rock with a single joint network and without the influence of groundwater, the surrounding rock mainly undergoes shear failure at the arch crown after tunnel excavation. When affected by groundwater, the failure of the surrounding rock on the left side of the tunnel is dominated by shear failure and the surrounding rock on the right side undergoes both shear and tensile failure. In the rock with a composite joint network and without the influence of groundwater, the surrounding rock after tunnel excavation mainly produces a small amount of damage at the junction of soft and hard strata. When the influence of groundwater in considered, largescale damage occurs to the surrounding rock near the tunnel. Two types of damage occur at the same time close to the tunnel, while shear damage is the main damage in the surrounding rock far from the tunnel

(2) For the rock with a composite joint network, the vertical displacements affected by groundwater are all greater than those without considering the influence of groundwater. The surrounding rock approximately $1 \mathrm{~m}$ from the arch crown is broken under the conditions of a single joint network and groundwater. The surrounding rock approximately $3.5 \mathrm{~m}$ from the arch crown is fractured and destroyed under the conditions of a composite joint network and groundwater

(3) For the rock with a single joint network, when groundwater is considered, the right sidewall is destroyed approximately $1 \mathrm{~m}$ from the monitoring point. In addition to the influence of groundwater, the difference in the displacement of the surrounding rock on either side of the tunnel is obviously affected by the bias load. When the tunnel is located in a rock with a composite joint network, the deformation of the jointed soft rock is significantly affected by groundwater. The surrounding rock within approximately $5.5 \mathrm{~m}$ from the measuring point undergoes separation failure. When there is no groundwater, the left sidewall is also damaged. Under the dual effects of joints and groundwater, the soft rock deforms considerably

\section{Data Availability}

All data supporting this study are included within the article.

\section{Conflicts of Interest}

The authors declare that there are no conflicts of interest regarding the publication of this paper.

\section{Acknowledgments}

The financial support for ongoing projects from the Open Fund of Innovation Institute for Sustainable Maritime Architecture Research and Technology (iSMART), Qingdao University of Technology (no. 2020-032), is greatly acknowledged.

\section{References}

[1] H. Kairong and F. Huanhuan, "Development trends and views of highway tunnels in China over the past decade," China Journal of Highway and Transport., vol. 33, pp. 62-76, 2020.

[2] M. F. Lei, L. M. Peng, and C. H. Shi, "Model test to investigate the failure mechanisms and lining stress characteristics of shallow buried tunnels under unsymmetrical loading," Tunnelling and Underground Space Technology, vol. 46, pp. 64-75, 2015.

[3] S. Chen, C. S. Qiao, Z. Yang, and C. Z. Qiao, "Application of stochastic joint network simulation to composite strata of shallow-buried long-span metro tunnels," Bulletin of Engineering Geology and the Environment, vol. 79, no. 4, pp. 20852107, 2020.

[4] X. Wang and M. Cai, "A DFN-DEM multi-scale modeling approach for simulating tunnel excavation response in jointed rock masses," Rock Mechanics and Rock Engineering., vol. 53, no. 3, pp. 1053-1077, 2020.

[5] N. Roy, R. Sarkar, and S. D. Bharti, "Prediction model for performance evaluation of tunnel excavation in blocky rock mass," International Journal of Geomechanics, vol. 18, no. 1, article 04017125, 2018.

[6] X. F. Deng, J. B. Zhu, S. G. Chen, Z. Y. Zhao, Y. X. Zhou, and J. Zhao, "Numerical study on tunnel damage subject to blastinduced shock wave in jointed rock masses," Tunnelling and Underground Space Technology, vol. 43, pp. 88-100, 2014.

[7] Y. Wang, J. Su, S. L. Zhang, S. Y. Guo, P. Zhang, and M. Q. Du, "A dynamic risk assessment method for deep-buried tunnels based on a Bayesian network," Geofluids, vol. 2020, Article ID 8848860, 14 pages, 2020.

[8] Y. Wang, Y. J. Zhang, Z. Zhu, M. Q. Du, and Y. Qi, "A novel method for analyzing the factors influencing ground settlement during shield tunnel construction in upper-soft and lower-hard fissured rock strata considering the coupled hydromechanical properties," Geofluids, vol. 2020, Article ID 6691157, 13 pages, 2020.

[9] N. Bahrani and P. K. Kaiser, "Influence of degree of interlock on confined strength of jointed hard rock masses," Journal of 
Rock Mechanics and Geotechnical Engineering., vol. 12, no. 6, pp. 1152-1170, 2020.

[10] Y. Zhao, Y. Wu, Q. Xu et al., "Numerical analysis of the mechanical behavior and failure mode of jointed rock under uniaxial tensile loading," Advances in Civil Engineering, vol. 2020, Article ID 8811282, 13 pages, 2020.

[11] H. Changjiang, F. Jun, J. Nan, Z. Yufeng, and H. Lin, “Analysis on the influence of rock joint characteristics on failure modeand stability of bedding tunnel," Chinese Journal of Underground Space and Engineering., vol. 16, pp. 599-607, 2020.

[12] S. Wu, K. Li, Z. Yang et al., "Complex analytical study of the stability of tunnel-surrounding rock in a layered jointed rock mass," Mathematical Problems in Engineering, vol. 2020, Article ID 5473059, 15 pages, 2020.

[13] M. R. Maleki, "Groundwater seepage rate (GSR); a new method for prediction of groundwater inflow into jointed rock tunnels," Tunnelling and Underground Space Technology, vol. 71, pp. 505-517, 2018.

[14] J. Moon and G. Fernandez, "Effect of excavation-induced groundwater level drawdown on tunnel inflow in a jointed rock mass," Engineering Geology, vol. 110, no. 3-4, pp. 33-42, 2010.

[15] H. Farhadian, H. Katibeh, and P. Huggenberger, "Empirical model for estimating groundwater flow into tunnel in discontinuous rock masses," Environment and Earth Science, vol. 75, no. $6,2016$.

[16] C. Shi, B. Yang, Y. P. Zhang, and J. X. Yang, "Application of discrete-element numerical simulation for calculating the stability of dangerous rock mass: a case study," International Journal of Geomechanics, vol. 20, no. 12, article 04020231, 2020.

[17] Q. B. Lin, P. Cao, J. J. Meng, R. H. Cao, and Z. Y. Zhao, "Strength and failure characteristics of jointed rock mass with double circular holes under uniaxial compression: insights from discrete element method modelling," Theoretical and Applied Fracture Mechanics, vol. 109, article 102692, 2020.

[18] I. Vazaios, N. Vlachopoulos, and M. S. Diederichs, "Assessing fracturing mechanisms and evolution of excavation damaged zone of tunnels in interlocked rock masses at high stresses using a finite-discrete element approach," Journal of Rock Mechanics and Geotechnical Engineering, vol. 11, no. 4, pp. 701-722, 2019.

[19] E. Wang, G. B. Chen, X. J. Yang, G. F. Zhang, and W. B. Guo, "Study on the failure mechanism for coal roadway stability in jointed rock mass due to the excavation unloading effect," Energies, vol. 13, no. 10, p. 2515, 2020.

[20] G. C. Zhang, Y. L. Tan, S. J. Liang, and H. G. Jia, "Numerical estimation of suitable gob-side filling wall width in a highly gassy longwall mining panel," International Journal of Geomechanics, vol. 18, no. 8, article 04018091, 2018.

[21] R. H. Cao, R. B. Yao, J. J. Meng, Q. B. Lin, H. Lin, and S. Li, "Failure mechanism of non-persistent jointed rock-like specimens under uniaxial loading: laboratory testing," International Journal of Rock Mechanics and Mining Sciences, vol. 132, article 104341, 2020.

[22] Q. B. Lin, P. Cao, and R. H. Cao, "Experimental investigation of jointed rock breaking under a disc cutter with different confining stresses," Comptes Rendus Mécanique, vol. 346, no. 9, pp. 833-843, 2018.

[23] P. L. P. Wasantha, P. G. Ranjith, and D. R. Viete, "Comparative study of the hydromechanical behavior of intact, horizon- tally jointed, and vertically jointed rocks under undrained conditions," Journal of Materials in Civil Engineering, vol. 28, no. 9, article 04016083, 2016.

[24] G. C. Zhang, Z. J. Wen, S. J. Liang et al., "Ground response of a gob-side entry in a longwall panel extracting $17 \mathrm{~m}$-thick coal seam: a case study," Rock Mechanics and Rock Engineering, vol. 53, no. 2, pp. 497-516, 2020.

[25] R. S. Yang, C. X. Ding, L. Y. Yang, and C. Chen, "Model experiment on dynamic behavior of jointed rock mass under blasting at high-stress conditions," Tunnelling and Underground Space Technology, vol. 74, pp. 145-152, 2018.

[26] Z. M. Chao, G. T. Ma, X. W. Hu, and G. Luo, "Research on anisotropic permeability and porosity of columnar jointed rock masses during cyclic loading and unloading based on physical model experiments," Bulletin of Engineering Geology and the Environment, vol. 79, no. 10, pp. 5433-5454, 2020.

[27] H. W. Jing, S. Q. Yang, M. L. Zhang, G. A. Xu, and K. F. Chen, "An experimental study on anchorage strength and deformation behavior of large- scale jointed rock mass," Tunnelling and Underground Space Technology, vol. 43, pp. 184-197, 2014.

[28] K. Wu, Z. S. Shao, and S. Qin, “An analytical design method for ductile support structures in squeezing tunnels," Archives of Civil and Mechanical Engineering, vol. 20, no. 3, 2020.

[29] Y. Xia, C. Zhang, H. Zhou et al., "Mechanical behavior of structurally reconstructed irregular columnar jointed rock mass using 3D printing," Engineering Geology, vol. 268, article 105509, 2020.

[30] Q. Jiang, X. T. Feng, Y. H. Gong, L. B. Song, S. G. Ran, and J. Cui, "Reverse modelling of natural rock joints using 3D scanning and 3D printing," Computers and Geotechnics, vol. 73, pp. 210-220, 2016.

[31] Y. T. Wang, X. P. Zhou, and Y. D. Shou, "The modeling of crack propagation and coalescence in rocks under uniaxial compression using the novel conjugated bond-based peridynamics," International Journal of Mechanical Sciences, vol. 128-129, pp. 614-643, 2017.

[32] X. P. Zhou, Y. T. Wang, Y. D. Shou, and M. M. Kou, "A novel conjugated bond linear elastic model in bond-based peridynamics for fracture problems under dynamic loads," Engineering Fracture Mechanics, vol. 188, pp. 151-183, 2018.

[33] X. P. Zhou, Y. T. Wang, and Q. H. Qian, "Numerical simulation of crack curving and branching in brittle materials under dynamic loads using the extended non-ordinary state-based peridynamics," European Journal of Mechanics - A/Solids, vol. 60, pp. 277-299, 2016.

[34] G. Yabin, Study on Deformation Characteristics and Controlling Measures of Unsymmetrically Loading Tunnels in Bedding Strata $[M D]$, Lanzhou Jiaotong University, Lanzhou, China, 2020.

[35] Z. Weihuan, Advanced Rock Mechanics, China Water Power Press, Beijing, China, 1990. 